\title{
'He'll Have To Go': Popular Music and the Social Performing of Memory
}

\author{
Nedim Hassan \\ ned1973@liverpool.ac.uk \\ University of Liverpool
}

\begin{abstract}
Studies of music listening have often relied upon what people say and write about listening in order to discuss its significance to memory. While this approach has provided useful insights into connections between musical activity and memory, this article will make clear that such an approach often neglects what people do when listening and remembering. This article will present an ethnographic case study focusing on John, a 64 year old man who, on the surface, seems to have great difficulty with coherently elucidating his memories. However, it will be revealed that musical performing constitutes a valuable resource for John; enabling him to communicate his memories in ways that are powerfully affective and to construct a positive sense of self-identity. Thus, the article will provide an insight into the potential advantages of utilising ethnographic research to attend to performative elements of music-related remembering, but it will also explore some of the methodological difficulties that are involved with this approach.
\end{abstract}

Key words: musical performing, memory, identity, embodiment, ethnography.

\section{Introduction}

In George Orwell's haunting novel Nineteen Eighty-Four the precious nature of peoples' memories is made strikingly evident. Winston, the central character, is depicted throughout much of the book as someone ruminating about the past. He is fearful that what he remembers may betray him to the Thought Police who punish 'non-conformist' thinking that challenges the totalitarian regime ran by Big Brother (the figurehead of the fictional political party in the novel). At the same time Winston is only too aware of the fragile nature of memories and how the past can be re-written to suit the needs of the powerful. In his job at the Ministry of Truth Winston's task is to continually re-write history, omitting certain details that had previously been established as 'truth'. 
Faced day-to-day with tasks that effectively obliterate history and call into question peoples' previous knowledge of the past, it is unsurprising that Winston recognises the significance of his personal memories. Indeed, throughout the early sections of the book there is a strong sense of the precariousness of such memories but also that these memories are firmly socio-cultural. Therefore, as well as the content of his memories, the ways in which Winston remembers events like sex within marriage as shameful and sordid are powerfully influenced by his way of life within a totalitarian society (Orwell, 2000 [1949], pp. 70-71). Furthermore, in the fleeting moments when Winston experiences pleasure, such as when he recalls the rhyme 'Oranges and Lemons' and begins to sing it in front of his lover, Julia, it is clear that memories (in this case a music-related one) are shaped by, recalled within and performed during social situations (Orwell, 2000 [1949], p. 153).

Though it may seem like a tangential example, Nineteen Eighty-Four's treatment of memory provides an instructive starting point for a consideration of the complex relations between musical activity and remembering. By focusing upon a case study taken from a long-term ethnographic research project conducted in a supported living scheme for four adults with learning difficulties (LD), this article will affirm that remembering is a socio-cultural process. As such it will be argued that it is vital to situate both acts of remembering (how remembering happens) and the products of remembering (what is remembered) within the everyday context of the person(s) doing the remembering. It will also explicate that musical activities can be instrumental to remembering and that they can greatly enhance the performing of memory. Thus, as in the fictional world of Nineteen Eighty-Four, remembering will be represented in this article as not purely a mental process, but an embodied practice.

Furthermore, as in the dystopian world of Orwell's novel, this article will argue that there can be much at stake with acts of remembering. This is especially the case for people with LD, whose 'pasts' have often been written about from institutional perspectives, rather than from personal ones. Remembering is clearly subject to power relations, particularly when considering whose memories are inscribed and written as 'history' and whose are excluded. Consequently, in the latter part of this article the process of ethnographic research and how this involved my remembering and my representations of others' memories will be reflected upon. Yet despite the concern to locate remembering as socio-culturally specific and subject to power relations, this article will also assert that musical activity has the potential to become a significant resource for remembering and, therefore, for the articulation of a sense of self.

\section{Music and Memory}

Scholars from various academic fields have discussed music's mnemonic power. The psychologist John Sloboda (1985) proposes that listeners remember music by discovering similarities and connections within the patterns and 
structures of musical compositions. Repetitions within musical pieces are important to this process. Anthony Storr argues that this is particularly the case with popular songs because they are: "simple, endlessly repeated and difficult to avoid" (Storr, 1992, p. 21). Considering music's importance to memory in general, the sociologist Tia DeNora suggests that music is an effective aid to memory for two reasons. Firstly, music is a "temporal medium", thus, unlike physical objects, music moves through time (DeNora, 2000, p. 66). Consequently, when specific pieces of music are "reheard and recalled" they become an effective device for recollecting those time periods in which the pieces of music were an accompaniment (DeNora, 2000, p. 67). Secondly, because people often actively shape their experiences by engaging with musical materials, for instance choosing to play a particular song in front of others, those materials can become significant "referents for experience" (DeNora, 2000, p. $67)$.

Returning to Storr's above point, it is clear that, while it is important to pay attention to music's specificity as a medium when exploring its relations with memory, it is also necessary to consider the mediation of music. Especially if we examine mediation in terms of transmission, it has been argued by some writers that music's presence in advanced capitalist societies is almost ubiquitous (Kassabian, 1999, 2000; Abercrombie \& Longhurst, 1998). ${ }^{1}$

As music can potentially be listened to within many areas of public life in such societies, this may have a distinct influence upon processes of remembering. For example, in his study of personal stereo users Michael Bull (2000) indicates that while they were negotiating urban spaces many of his interviewees chose to listen to tapes that were personally meaningful to them. Bull suggests that, for personal stereo users, listening to such meaningful tapes "reminds them of the significance of their own biography in spaces devoid of interest and significance" (Bull, 2000, p. 24). Therefore, through personal stereo use the soundtracks to a person's past can be utilised within potentially alienating, impersonal environments in order to remind them of 'who they are'.

However, clearly music's importance to peoples' memories cannot be explored by solely considering technological mediation; neither can it be assessed by only paying attention to textual characteristics. Indeed, as various writers have argued, to isolate 'music' as a text is to reify 'it' and obscure its nature as activity enacted within specific socio-cultural contexts (Cook, 2003; Small, 1998). A number of scholars have conducted qualitative research that supports this argument; producing studies that provide significant insights into how musical activities connect with personal memories for specific individuals or groups.

For instance, DeNora's aforementioned study Music in everyday life (2000) makes problematic the notion that it is possible to clearly separate 'music' from its moment of reception when considering music-related memories. Discussing the recollections of her interviewees, DeNora writes that: 
...on rehearing music that helped to structure, to inform experience, respondents describe how they are able to relive that experience; the study of human-music interaction thus reveals the subject, memory and, with it, self-identity, as being constituted on a fundamentally socio-cultural plane where the dichotomy between 'subjects' and 'objects' is, for all practical purposes, null and void (DeNora, 2000, p. 67).

Therefore, when DeNora explores how one of her respondents, Lucy, listens to Schubert's Impromptus, she makes clear that Lucy's memories of her late father playing the piece on the piano when she was a child had a strong bearing on her engagement with it (DeNora, 2000, pp. 41-43). Yet, in order to assess the affective power of Impromptus for Lucy it is not sufficient to solely pinpoint her memories, just as it is inadequate to analyse musical structure in isolation. Rather, DeNora affirms that a range of contextual factors have to be considered because she writes: "Music's effects are generated by a describable addition, whose sum is greater than its parts: music, plus the ways that the recipient (in this case, Lucy) attends to it, plus the memories and associations that are brought to it, plus the local circumstances of consumption" (DeNora, 2000, p. 43).

DeNora's model is very helpful for a consideration of how individuals engage in musical activities, particularly during private moments where music listening is a primary activity that is bound up with processes of remembering. As well as DeNora, other researchers such as Tacchi (2003), van Dijck (2006) and Kenney (1999) have explored how music is crucial to peoples' recollections of their past. In turn, these studies emphasise that such recollections are an important element in the construction of self-identity. Furthermore, van Dijck makes clear that: "Memories attached to songs are hardly individual responses per se; recorded music gets perceived and evaluated through collective frameworks for listening and appreciation" (van Dijck, 2006, p. 367). Consequently, not only is it necessary to consider that individuals' self-identities are likely to be fostered through music-related recollections that involve other people, it is also necessary to recognise that music-related memories can create a sense of collective identity. ${ }^{2}$

For example, in Kenney's (1999) study of the survey responses of American record buyers conducted for Thomas A. Edison Inc. in 1921 he illustrates that some customers' comments articulated anxieties regarding familial and national identity. American family values were seen by some of those surveyed as becoming eroded by newer forms of music (notably types of jazz such as ragtime). Consequently, solace was sought through listening to recordings (such as American folk songs) that were associated with "a more tranquil time of family continuity" (Kenney, 1999, p. 10). However, again it is vital to consider context with this example. As Kenney suggests, these memories were inscribed at a particular period in US history when American urban life was changing in the face of rising industrialisation (Kenney, 1999, p. 10). Memories, therefore, are contingent upon social change and their content is influenced more 
by the exigencies of the present than the past (van Dijck, 2006, p. 362). This is a theme that will be returned to later, when the importance of immediate social relations to the articulation of music-related memories will be discussed.

The qualitative studies mentioned so far are similar in that when discussing the connections between music and memory they tend to rely upon what sociologist Paul Connerton would call inscribing practices (Connerton, 1989, p. 73). These are usually intentional practices of trapping and holding information for the purposes of remembering events, people, objects, and so on. In the case of the studies mentioned above, the inscribing practices that were focused upon during analysis of music-related memories included: interview transcripts; surveys and internet chat room dialogue. While it is important to analyse such sources, it is also crucial to recognise that memories are embodied. Consequently, it is imperative to pay attention to what Connerton calls "incorporating practice" - peoples' bodily activities that convey (either intentionally or unintentionally) messages about their memories (Connerton, 1989, p. 72). In short, when considering music-related memories it is necessary to examine both what is remembered (what is uttered, written, sung, danced) and how remembering occurs (body actions, gestures, facial expressions, comportment, deportment, periods of silence and contemplation).

Sara Cohen (1995) acknowledges this in an exploration of how music relates to peoples' experiences of place. Drawing upon regular interviews with Jack Levy, an 88 year old Jewish man from Liverpool, she explicates that Jack re-enacts his past during their conversations about his memories of dancing in Liverpool during the 1920s and 1930s. In recounting his experiences Jack performs his memories, Cohen describes this as follows:

Sitting on his sofa, he sways his torso and arms, closing his eyes in an expression of blissful engrossment, attempting to convey to me the physical attraction of the dance and the heightened sensuality and pleasure it evoked, displaying a sense of pride in the talents he had as a dancer and the proficiency and skill with which he mastered the steps (Cohen, 1995, p. 437).

Cohen emphasises that repetitive movements (such as dance steps) or journeys (such as those to and from work) are deeply affective and memorable for Jack. Dancing to music is associated with repeatable pleasures; ways of moving that can be re-enacted even if they are far removed from their original contexts. As will be emphasised later, such re-enactments can become fundamental to the construction of self-identity.

Cohen's article is one of the few studies concerned with exploring the performing of music-related memories. Indeed, Connerton (1989) argues that the performative elements of memory have been underplayed in the history of the study of hermeneutics in general. He mainly attributes the relative absence of any examination of incorporated practices to their distinctive nature; asserting that such practices require a lack of reflexive consciousness in order to be performed well (Connerton, 1989, p. 101). While this may be the case with 
certain kinds of music-related remembering, for instance the habitual remembering that Ben Anderson (2004) examines when considering practices such as playing CDs, the performative remembering that will be elucidated below was enacted with a stronger degree of reflexivity. ${ }^{3}$ Although it was part of a regular routine and not extraordinary behaviour for the person concerned, it will be revealed that this performative remembering was neither a habitual process that involved the replication of physical actions for practical purposes nor the straightforward recall of an "inert" past (Anderson, 2004, p. 8). On the contrary, as will be seen, this remembering was far more social and interactive in nature.

Thus, in the main sections that follow, the value of studying the performing of memories and the roles that musical activities can have during such performing will be explored. This exploration will be accomplished through an examination of a specific ethnographic case study drawn from a research project that focused upon the significance of music in the everyday domestic lives of a group of people with LD. Then, later in this article, there will be a consideration of the methodological implications of this ethnographic approach. Prior to all this, however, it is necessary to briefly outline why the study of the memories of people with LD is important.

\section{Memory and People with Learning Difficulties}

The inscription of memories is not a neutral process, but one that is subject to inequality of access. For instance, if someone wants to contribute to an internet chat room discussion about their most fondly remembered songs from a previous decade then their participation is dependent upon various factors. They would need access to a computer that had the internet and the appropriate software; they would also need computer literacy as well as basic literacy in order to communicate their memories in this way. If these technological and intellectual resources are not possessed together with the sufficient economic capital then this type of memory-centred activity becomes difficult.

Inequality of access to resources that enable people to communicate aspects of their past is an issue that has been particularly pertinent for people with LD. This is because access to resources for inscribing their past and, indeed, communicating self-identity has often been denied to them. As the subjects of specific medical and political discourses, groups and individuals with LD have frequently had their lives shaped and mapped out by various organisations that decide what is 'good for them' as well as 'who they are' (Digby, 1996; Race, 2002). The histories of people with LD in Britain have largely featured an absence of any specific consideration of the experiences of the people being written about. Providing a summary of how we should understand the histories of people with LD from an institutional point of view Atkinson et al. write that: 
The history of learning disabilities has thus been part of much broader studies of eugenics and genetics, of the development of education and special education, of psychology and psychiatry, and of developments in the organisation and policies of the mental health services in general (Atkinson et al. 1997, p. 5).

Atkinson et al. go on to point out that, while there has been a recent increase in interest in examining the histories of people with LD in-depth, the vast amount of research in this area still tends to produce histories derived solely from official documents and accounts from doctors, politicians and practitioners. Thus, the views of staff and residents from establishments for people with LD have tended to be subordinated.

While this article does not aim primarily to contribute to the reconstruction of the history of people with LD in Britain through oral history (which is the central concern of Atkinson et al.), it will prioritise the experiences of one man with LD in a specific setting by drawing upon ethnographic data derived mainly from observations. Therefore, by focusing specifically upon the personal music-related memories of a person with LD, this article will take a small step towards shedding light upon previously hidden histories. As will be seen, in order to achieve this it was vital to pay attention to performative aspects of remembering.

\section{'He'll Have To Go': Musical Activity and the Presentation of the Past in the Present}

The ethnographic case study that will be discussed focuses upon the reception of a single song by John, a man with LD who lives in a supported living scheme on a housing estate in the North West of England. ${ }^{4}$ I first began working with John as a part-time support assistant in January 2000. Although there is a significant age gap between us (John is 30 years older than me), we began to develop a friendly social relationship as I helped to support him with various daily routines.

I first encountered the song 'He'll Have To Go' when I began supporting John with his bathing routine on a regular basis. After I had become familiar with his morning routine, it soon became apparent that John liked to have music playing in his bedroom while he was being supported to get dressed after his shower. Gradually it became clear that one of John's favourite singers was Jim Reeves. Although John would often ask me to "put music on", when asked to clarify which CD I should place in his stereo system John would only specify one performer which was Jim Reeves. In fact, Jim Reeves was the only specific performer that I heard John request. Although he remembered the tunes and lyrics to a number of songs, Jim Reeves was the only artist name John seemed to remember. Thus, it became apparent that Jim Reeves is an artist who is dear to John; he is a singer who is treasured and remembered. 
In September 2000 I gained permission to conduct ethnographic research in John's house that he shares with three other people. The research had the broad aim of exploring the significance of music in everyday domestic life for the residents of the particular supported living scheme. Therefore, amongst other things, the research approach was designed to examine the importance of popular songs (like 'He'll Have To Go') and artists to the residents. The principal method that was utilised during research was participant-observation, although supplementary methods such as informal interviews with residents and staff were also adopted.

While the term 'participant-observation' has been used to denote the main type of ethnographic fieldwork that was utilised during research, it should be pointed out that I was not a 'participant-observer' in a straightforward sense. This is because I was primarily seen in the environment in which the ethnographic research was based as a support assistant, not a researcher. ${ }^{5}$ Nevertheless, such a research approach was adopted with the aim of explicating the significance of music in the everyday lives of the residents without damaging the rapport and social relationships that had been built up with them. Data from observations of activities that I witnessed and participated in as well as conversations that I heard was primarily recorded in a research diary that was completed away from the house where fieldwork took place. The implications of this approach will be discussed later in the article.

As research progressed I became increasingly interested in John's reception of 'He'll Have To Go'. His affection for Jim Reeves' music seemed to be strongly connected to his past and to the times when he lived with his mother and father. This was made apparent when an interview was conducted with John's sister at her house (with John in attendance). She indicated that John's preference for Jim Reeves stems from listening to and singing along with his father's records as a young man. Indeed, Jim Reeves was the first name that his sister and her husband remembered being associated with the records that John used to listen to. Thus, the songs of Jim Reeves seem to be intimately connected with John's past. They are, as his sister suggested, "loved" by John because of their association with his father (in fact the most common descriptive word that she used when discussing John's preferences was 'love') (Interview, 19 September, 2004).

Whilst individual oral narratives about the past such as those told by John's sister should not be seen to represent 'historical reality', they are important for they reveal her sense of the past (Tosh, 1999 p. 199). Therefore, although they may not represent an entirely accurate account of John's musical practices at the time when he lived with his father and mother, his sister's words provide an insight into her sense of the past in the present. For her, as with John, Jim Reeves is someone who she remembers. Furthermore, the sense of past that she recalls in this interview is recounted with affection. These were fond recollections that imbued the records that her father and John listened to together with great importance. 
Moreover, it was not only his sister's oral testimony or John's expression of a preference for Jim Reeves that led to an investigation of the importance of this particular artist. Rather, it was John's actions while listening to Jim Reeves and the song 'He'll Have To Go' that initially led to an exploration of the connections between his past and the songs of Jim Reeves. These actions will be focused upon shortly, but first it is necessary to discuss the specifics of 'He'll Have To Go' further.

'He'll Have To Go', which was originally released by Reeves in 1959 and written by Joe and Audrey Allison in the same year, is a gently paced ballad that typifies the Nashville sound of country music in the USA that was commercially successful during the 1960s. It is a simple and uncluttered song in terms of musical arrangement. The general structure of the song is a very common one amongst popular songs. It has a simple AABA structure and its time signature features a soft swinging tempo. Reeves' vocals are accompanied by a vibraphone, piano, electric bass and acoustic guitar. His voice is clear and distinctively deep and Reeves' vocals are prominent in the song's mix; indeed he was very careful with his vocal style both in terms of phrasing and proximity to the microphone (Escott, 2002). Consequently, because of this vocal clarity and clear lyrics 'He'll Have To Go' was a suitable song for John to sing along with. Its gentle swinging rhythm also makes it easy to sway along with. As will be seen below, while the musical structure of the track may have afforded particular movements and musical activities, John performed certain actions during this song that cannot merely be explained with reference to this structure.

When his The Best of Jim Reeves (RCA 1996) CD was played as he was being supported to get dressed while sat on his bed, John's reactions were usually mixed. Sometimes he would sing along enthusiastically with certain lines from the first few tracks, but on other occasions he would not explicitly respond to any of them. In contrast with the earlier songs on his Jim Reeves compilation album, when 'He'll Have To Go' came on John tended to respond differently. He would frequently pay more attention to it and seemed to have an intimate knowledge of the track, displaying distinct kinds of performing. John demonstrated a strong knowledge of the lyrics of 'He'll Have To Go' and he would sing along to the verses quite well despite his speech impediment. In particular, when listening to the opening verse John would frequently sing along. When he was singing the first line "Put your sweet lips a little closer to the phone" John would often sustain Jim Reeves' vocal phrasing quite accurately, especially during the second half of that line. He would emphasise the phrase "closer to the phone"; stressing the word "closer" in accordance with Reeves. This indicated that John had intimate knowledge of this part of the song as he knew Reeves' vocal inflections. Although John often wouldn't get much further than the second line "Let's pretend that we're together all alone" when singing, his performing of the song was also significant because of his enacting of what he called "exercises".

As the song continued, John would usually utter the word "exercises" and, remaining sat on the bed, he would then put his hands by his sides and begin to 
sway gently from side to side. This was a regular occurrence whenever John listened to 'He'll Have To Go' and his association of the song with "exercises" was not merely confined to his bedroom but also took place in other situations. ${ }^{6}$ Yet it was during our social interactions in his bedroom that his performing of "exercises" was most pronounced. The performing was intriguing and it was enacted with enthusiasm and vigour. Yet unfortunately when asked about where the association with 'He'll Have To Go' and "exercises" came from John found it difficult to provide more information. Indeed, in general John's communication was relatively fragmentary; he was comfortable responding to simple 'yes' or 'no' questions and with asking basic questions (his favourite one was to request a cup of tea). However, when it came to providing information about past events and people, John usually provided snippets of details, rather than a coherent verbal narrative.

Thus, to return momentarily to DeNora's theories outlined during the first part of this article, while 'He'll Have To Go' and the exercises that accompanied it seemed to be a significant "referent" for John's past experiences, it remained difficult to ascertain precisely which experiences these musical materials and activities referred to (DeNora, 2000, p. 67). In order to try and find out more about the association between 'He'll Have To Go' and the exercises that John enacted, I asked his sister about this during an interview. She told me that, while she didn't remember any particular songs being explicitly connected to exercise routines, she did remember how John was involved in an exercise class at a day centre that he went to. He would then come home to his mother and father and show them the exercises that he'd learnt at the centre. She went on to suggest that this was around forty years ago, which would have coincided with Jim Reeves' most commercially successful period in Britain between the early to mid-1960s. ${ }^{7}$

Ultimately, only tentative conclusions were able to be reached when examining the origins of the connections between 'He'll Have To Go' and John's performing of exercises. However, as suggested earlier, it is not simply the content of memories that is important with this case study, rather it is the process of remembering. It has been established that inequality of access to resources for inscribing personal memories has historically been a problematic issue for people with LD. While John was not inscribing his memories during musical activity, he was able to effectively communicate aspects of them through performing. In this case, therefore, musical performing was an accessible, flexible resource for the communication of past events for an individual who had difficulties conveying those events through a coherent verbal narrative.

Paying attention to John's utterances and incorporated practices provided striking insights into his past (Connerton, 1989, p. 72). Despite not being able to provide a detailed account or narrative of his fandom, John's musical performing revealed the significance of Jim Reeves to him. Reeves was a musician he knew; someone who was treasured and remembered in association with other people, events and places. Even if his sister had not been contacted to subsequently provide further information about these associations, it was clear from John's performing that the musical activities he associated with Jim Reeves were 
powerfully affective. Such affective dimensions of past experiences that, as we've also seen with Cohen's (1995) research, can be so effectively 'brought to life' through performing are irreducible. That is, they cannot adequately be articulated through other forms of communication such as verbal or written accounts. As with a previous article examining a different ethnographic case study (Hassan, 2008a), it is vital to stress here that what Penelope Gouk calls "embodied knowledge" - knowledge acquired and displayed through bodily actions - is equally deserving for scholarly attention as knowledge generated by cognitive means (Gouk, 2000, p. 22). Of course, the difficulty with translating this approach into academic praxis lies in the strong reliance researchers have upon inscribing their findings and this issue will be broached shortly. Firstly, as a precursor to this methodological discussion it is necessary to provide further exploration of the significance of the case study described above.

\section{Memory, Social Interaction and Identity}

It has been argued that musical performing to 'He'll Have To Go' was an effective resource for John to communicate his memories. At this juncture it is pertinent to consider the implications of this activity a little further. The importance of John's engagement with 'He'll Have To Go' was not simply related to the song providing him with an avenue to reflect on his past. To pursue such an argument would be to delimit 'the music' as separate from his performing and from the context in which performing took place. Rather, John's musical activities during the playing of 'He'll Have To Go' had significance on a number of levels.

Firstly, it is imperative to reiterate that John was performing his memories. Performing, musical or otherwise, is a form of self-presentation and as such it provides communication about the self (Goffman, 1959; Auslander, 2006). As l've argued elsewhere, such self-presentation can serve to (wittingly or unwittingly) communicate with the self or to other people (see Hassan, 2008b; Hassan, 2010). In the case study described above, John's presentation of his memories through musical performing took place in front of me. As was made clear during the earlier discussion of existing literature on music and memory, other scholars have asserted that it is vital to place music-related remembering within a specific socio-cultural context because it frequently involves other people and often contributes to a collective sense of identity (DeNora, 2000; van Dijck, 2006). Therefore, it is clear that with the case study above, while John was remembering through musical activity, he was also interacting. Consequently, it seems that one of the pleasures involved with engaging with 'He'll Have To Go' for John was in relation to the sharing of his memories with another person.

While this process of sharing involved John telling me something about his past, this communicative act also had implications for our ongoing social relationship. It enabled me to learn something about John's self-identity and provided ideas that I was able to investigate further. Consequently, this process underlines the earlier point made in this article when considering the work of Kenney (1999) and van Dijck (2006). Namely that remembering is strongly 
influenced by the immediacies of the present, as well as the recollection of the past. In this sense, John's engagement with 'He'll Have To Go' was similar to what Jo Tacchi discusses as "practical nostalgia" (Tacchi, 2003, p. 291). This is a type of remembering that involves making connections with a past experience in order to enhance future relationships. Not only did John's performing inspire me to investigate further the content of his memories which necessitated developing closer links with his sister and visiting her with John, it also had an impact on our future social relationship. This is because as I remembered that John had performed to Jim Reeves in particular ways, I was more inclined to pay attention whenever he requested the artist or when he listened to Reeves' recordings. I was also more inclined to support John to listen to Jim Reeves after discovering something about the pleasures he seemed to derive from engaging with 'He'll Have To Go'.

The personal and social value of John's memory-related performances was substantial. Not only did his performing help to foster stronger social relationships by conveying aspects of his 'past' self, it facilitated the construction of a sense of self-identity in the present. Indeed, there were many instances during his everyday life where John seemed to thrive on being the focal point of the attention of others and musical performing was one way of garnering such attention. He would often seize the opportunity to sing along to an advertising jingle featured on the television or the radio. The significance of this everyday performing for the articulation of self-identity has been explored in more depth elsewhere (see Hassan, 2008b and Hassan, 2010). For the purposes of this article it is necessary to identify John's performing of 'He'll Have To Go' as related to this type of everyday performing in so far as it too was enacted with enthusiasm in front of another person (me). For John, such performing offered a productive means of effectively implying that 'this is me'. That is, musical performing was an effective medium for conveying a persona for John, as well as for conveying his memories. Therefore, as musical performing was a vehicle for remembering in the above case study, it is clear that remembering needs to be seen as part of John's strategies for self-presentation and social interaction.

The psychologist Susan Engel asserts that remembering often has a strong social dimension. She argues that when interactions like those that occurred as John was performing to 'He'll Have To Go' in front of me take place: "the process of remembering depends as much on motivation and social context as it does on any neural network" (Engel, 1999, p. 9). Thus, Engel provides a reminder that it is highly likely that if John had not built up a trusting relationship with me and if he was not in the relatively private space of his bedroom then his memory-related performances might not have occurred at all. Engel's point about the importance of considering context raises the spectre of an issue that was alluded to earlier; that of my role in the construction of John's memories as both an ethnographer and support assistant. This is an issue that will be addressed in the final section of this article. 


\section{Memory and Ethnography}

It was asserted earlier that John, like many people with multiple learning difficulties, found it difficult to articulate his memories in ways that other people might take for granted. He could not inscribe his memories in the form of a diary, nor could he (on his own) take photographs to mark past occasions, and he struggled to form a coherent verbal narrative when describing past events. On the other hand, musical performing was an accessible resource for John that enabled him, if not to produce a narrative of his past, then to successfully convey some significant aspects of it and enabled him to convey something of the affective power of past experiences.

Yet, it is undeniable that as a support assistant and as an ethnographer I also had a strong role in processes relating to the articulation of John's memories. My presence had an influence on these processes in a number of ways. Firstly, I had a part in initiating John's listening to Jim Reeves' songs because I gave him the option of choosing a CD to listen to while getting dressed. Moreover, without my assistance with actually placing the CD into his stereo system and pressing the play button (something that John found difficult to accomplish), music would not have been heard. Therefore, on a practical level, John's access to musical materials was dictated by my agency and without this the performing of memory that ensued would not have occurred in the same way.

Secondly, by writing about John's memory-related activities in this account, it is clear that I am re-presenting those activities in a medium that is far removed from the context in which they were initially conveyed. This scholarly account is providing permanence to actions and events that were fleeting. It is inscribing the content and processes of remembering, when, as it has been argued, these phenomena were largely understood through attending to incorporating practices. Obviously there is an inadequacy with such an approach because events that had strong performative and affective dimensions cannot easily be translated into words on a page.

Furthermore, this approach betrays another significant problem that has plagued previous ethnographic researchers. This concerns the power relations between the ethnographer and their research subjects, particularly once the ethnographer is no longer 'in the field'. In his work on the ethics associated with life writing G. Thomas Couser (2004) elucidates that when people write about the lives of others they face a distinct ethical dilemma. Namely that their relationships with their 'subject(s)' during social interactions are profoundly different to those that the writer has with their pages and with their readership. Thus, once an ethnographer no longer spends time in the environment where fieldwork was conducted, they are faced with very different types of representational activity. Whereas during fieldwork their relationships with research subjects would have been largely dialogical, when it comes to 'writing up' that fieldwork in the form of field notes or other written forms such relationships become monological. In other words, during ethnographic writing scholars often have to rely on their interior monologues to represent past events and activities involving their research 
subjects. No matter how detailed field notes are, they will undoubtedly be supplemented by the ethnographer's memories of the people they interacted with.

Consequently, during this article it is my memories of John's reception of 'He'll Have To Go', coupled with a consideration of field notes and an interview with his sister, that have been instrumental in the construction of John's 'memories'. It could even be suggested that, although it has been argued that John was able to communicate a sense of self-identity through the musical performing of memories, this 'self-identity' has largely been constructed through my writing. 'John', therefore, could be viewed as somewhat like a fictional character in a dual sense: he is represented by a pseudonym and he is reduced to an actor engaged in musical performing in order to make various points about the relations between musical activity and memory.

Yet, although my voice dominates this text and while I have undoubtedly represented people, events and activities in ways that do not 'capture' the complexity of actuality, this does not invalidate the research work. On the contrary, this article has helped to reveal the precarious nature of ethnographic research that focuses upon musical activities occurring within everyday routines. Like practices of remembering, ethnography is permeated by a range of factors that include reliance on social relationships; presentation in front of others (both in the field and to readers) and past experiences which combine both embodied and cognitive knowledge of what has gone before. A challenge for ethnographic researchers that has been identified by other writers is to acknowledge these various influences and to lay bare the contextual factors that shaped the production of their written accounts (see for instance, Clifford, 1986; Van Maanen, 1995; Titon, 1997).

An additional challenge that has been revealed during this article is for ethnographers to recognise the roles of their memories in the construction of their written accounts (see also Biklen, 2004). As Barz (1997) and Hastrup (1995) have suggested, fieldwork is a rich activity that involves sharing experiences with other people. Consequently, while field notes can jog memories, researchers should not be hesitant when trying to recount those memorable shared moments that weren't 'recorded' in field diaries or that were not easily translated into writing (see also Hassan, 2008a).

\section{Conclusions}

This article has explicated how John communicated his memories during engagement with the Jim Reeves song 'He'll Have To Go'. It has been argued that his remembering was distinctly performative and profoundly social; being influenced by the immediate social context in which it occurred. This account has also highlighted the way that relatively small instances of such activity have the potential to provide profound insights into personal history and self-identity. At the 
same time, it has asserted that these instances can be precarious in that they are subject to issues of access and power.

As many contemporary societies increasingly strive to afford citizens access to digital technologies that enable them to inscribe information about their selves, including their memories, cultural activities that help to perform identity in front of others should not be overlooked. As the above case study has made clear, musical activities can be a powerful resource for the articulation of memories and a sense of self-identity, especially for people who often have other avenues of expression closed to them. It is vital that these activities are carefully attended to, even if they are not easily inscribed or translated into a coherent narrative. Attempts to accomplish this may then assist in providing insights into how phenomena like music fandom and performing are experienced, as well as narrated.

\section{Notes}

1. The notion of 'mediation' is used here in rather narrow terms to refer to the medium in which music is disseminated. For a more rigorous examination of the differing ways that the concept can be applied to music please see Negus (1996).

2. Clearly, the construction of a sense of collective identity is not a neutral process, but one that is often related to specific political or ideological goals. For instance, Hesmondhalgh (2001) and Brocken (2003) have suggested that discourses relating to the construction of the musical styles labelled 'Brit pop' and 'folk' involved constructing fallacious notions of a continuity with a musical past (an 'English' tradition) in order to serve specific political agendas.

3. See also Bergson (2004 [1912]) for an influential discussion of the habitual dimensions of remembering.

4. Pseudonyms are adopted throughout this account in order to ensure confidentiality.

5. My job role entailed a number of responsibilities to the people living and working in that establishment that had to be prioritised above research interests. Furthermore, this role necessitated the involvement in particular power relationships with the residents in the supported living scheme because they were reliant upon me supporting them with various everyday needs. See my unpublished doctoral thesis (2008b) for more details of this role.

6. For instance, when we were travelling in a people carrier on our way to a holiday in York in the North of England along with another resident and member of staff, John was sat in the back of the vehicle when I put one of his other Jim Reeves compilations on the $C D$ player. When 'He'll Have To Go' came on John again associated it with "exercises" even though the song was heard in a very different listening situation to that in his bedroom.

7. The interview with John's sister was conducted in 2004 and forty years prior to that in 1964 Reeves released his two most successful hits: 'Welcome to my world' and 'I love you because'. The former single 450000 copies in 1964, while the latter would go on to sell one million copies during the same year. 'He'll Have To Go' would have already been a well known song in the mid-1960s having been released in March 1960 and eventually going on to spend thirty weeks in the British charts, peaking at number twelve (Guinness World Records, 2002, p. 394). 


\section{Acknowledgements}

Special thanks must go to Sara Cohen and Hae-Kyung Um for their support and advice during the ethnographic research upon which this article is based. Thanks must also go to Holly Tessler for her wise advice during the preparation of this piece. Finally, I am indebted to 'John', his sister and brotherin-law, and my former colleagues and friends at 'Orwell Street' for their support with this research.

\section{References}

Abercrombie, N. \& Longhurst, B. 1998. Audiences: A Sociological Theory of Performance and Imagination, Sage, London.

Anderson, Ben. 2004. "Recorded music and practices of remembering". Social \& Cultural Geography, Vol. 5, No. 1, pp. 3-20.

Atkinson, D., Jackson, M. \& Walmsley, J. 1997. Forgotten Lives: Exploring the History of Learning Disability, BILD Publications, Kidderminster.

Auslander, Philip. 2006. "Musical Personae". The Drama Review, Vol. 50, No. 1, pp. 100-119.

Barz, Gregory F. 1997. "Confronting the Field (Note) In and Out of the Field:

Music, Voices, Text, and Experiences in Dialogue" in Barz, G. F. \& Cooley, T. J. eds. Shadows in the Field: New Perspectives for Fieldwork in Ethnomusicology, Oxford University Press, Oxford, pp. 45-62.

Bergson, Henri. 2004 [1912]. Matter and Memory, Dover Publications, New York.

Biklen, Sari Knopp. 2004. "Trouble on Memory Lane: Adults and Self-

Retrospection in Researching Youth". Qualitative Inquiry, Vol. 10, No. 5, pp. 715730.

Brocken, Michael. 2003. The British Folk Revival, 1944-2002, Ashgate, Aldershot.

Bull, Michael. 2000. Sounding out the City: Personal Stereos and the Management of Everyday Life, Berg, Oxford.

Clifford, James. 1986. "Introduction: Partial Truths" in Clifford, J. \& Marcus, G. E. eds. Writing Culture: The Poetics and Politics of Ethnography, University of California Press, Berkeley, California, pp. 1-26.

Cohen, Sara. 1995. "Sounding out the City: Music and the Sensuous Production of Place". Transactions of the Institute of British Geographers, Vol. 20, winter, pp. 433-446. 
Connerton, Paul. 1989. How Societies Remember, Cambridge University Press, Cambridge.

Cook, Nicholas. 2003. "Music as Performance" in Clayton, M., Herbert, T. \& Middleton, R. eds. The Cultural Study of Music: a critical introduction, Routledge, London, pp. 204-214.

Couser, G. Thomas. 2004. Vulnerable Subjects: Ethics and Life Writing, Cornell University Press, Ithaca, New York.

DeNora, Tia. 2000. Music in Everyday Life, Cambridge University Press, Cambridge.

Digby, Ann. 1996. "Contexts and Perspectives" in Wright, D. \& Digby, A. eds. From Idiocy to Mental Deficiency: historical perspectives on people with learning disabilities, Routledge, London, pp. 1-22.

Engel, Susan. 1999. Context is Everything: The Nature of Memory, W. H. Freeman and Company, New York.

Escott, Colin. 2002. Roadkill on the Three-Chord Highway: art and trash in American popular music, Routledge, London.

Goffman, Erving. 1959. The Presentation Of Self In Everyday Life, Penguin, Middlesex.

Gouk, Penelope. ed. 2000. Musical Healing in Cultural Contexts, Ashgate, Aldershot.

Hassan, Nedim. 2008a. "When words are not enough: Exploring music reception and autistic experience". Popular Narrative Media, Vol. 1, No. 1, pp. 67-84.

Hassan, Nedim. 2008b. Hidden Musical Lives: The Roles and Significance of Music in Everyday Life at a Supported Living Scheme, PhD thesis, University of Liverpool, Liverpool.

Hassan, Nedim. 2010. "Singing to Your Self? Momentary Musical Performing and the Articulation of Identity" in Hassan, N. \& Tessler, H. eds. Sounds of the Overground: Selected papers from a postgraduate colloquium on ubiquitous music and music in everyday life. International Institute for Popular Culture, Turku, Finland, 21 March, <http://iipc.utu.fi/publications.html>

Hastrup, Kirsten. 1995. A Passage to anthropology: Between experience and theory, Routledge, London.

Hesmondhalgh, David. 2001. "British Popular Music and National Identity" in Morley, D. \& Robins, K. eds. British Cultural Studies, Oxford University Press, Oxford, pp. 273-286. 
Kassabian, Anahid. 1999. "Popular" in Horner, B. \& Swiss, T. eds. Key Terms in Popular Music and Culture, Blackwell Publishers, Oxford, pp. 113-123.

Kassabian, Anahid. 2002. "Ubiquitous listening" in Hesmondhalgh, D. \& Negus, K. eds. Popular Music Studies, Arnold, London, pp. 131-142.

Kenney, William Howland. 1999. Recorded Music in American Life: The Phonograph and Popular Memory, 1890-1945, Oxford University Press, Oxford.

Negus, Keith. 1996. Popular Music in Theory, Polity, Cambridge.

Orwell, George. 2000 [1949]. Nineteen Eighty-Four, Penguin, London.

Race, David. 2002. "The Historical Context" in Race, D. G. ed. Learning Disability - A Social Approach, Routledge, London, pp. 23-52.

Riesman, David. 1990 [1950]. 'Listening to Popular Music' in Frith, S. \& Goodwin, A. eds. On Record: Rock, Pop, and the Written Word, Routledge, London, pp. 113.

Sloboda, John A. 1985. The Musical Mind: The cognitive psychology of music, Oxford University Press, Oxford.

Sloboda, J. A. \& O' Neill, S. 2001. "Emotions in everyday listening to music" in Juslin, P. N. \& Sloboda, J. A. eds. Music and Emotion: Theory and Research, Oxford University Press, Oxford, pp. 415-430.

Small, Christopher. 1998. Musicking: The Meanings Of Performing And Listening, Wesleyan University Press, Hanover, NH [USA].

Storr, Anthony. 1992. Music and the Mind. HarperCollins, London.

Tacchi, Jo. 2003. "Nostalgia and Radio Sound" in Bull, M. \& Back, L. eds. The Auditory Culture Reader, Berg, Oxford, pp. 281-295.

Titon, Jeff Todd. 2003. "Textual Analysis or Thick Description" in Clayton, M., Herbert, T. \& Middleton, R. eds. The Cultural Study of Music: a critical introduction, Routledge, London, pp. 171-180.

Tosh, John. 1999. The Pursuit of History, Longman, Harlow, Essex. Third Edition. van Dijck, José. 2006. "Record and Hold: Popular Music between Personal and Collective Memory". Critical Studies in Media Communication, Vol. 23, No. 5, pp. 357-374.

Van Maanen, John. ed. 1995. Representation in Ethnography, Sage, Thousand Oaks, California. 


\section{Discography}

Jim Reeves. 1996. The Best of Jim Reeves, RCA, 1 July, UK.

\section{Interview}

Interview with Beryl. 2004. Unpublished audio interview, 19.9.04, 28 minutes, Lancashire, UK. 